\title{
Microfluidic on-chip biomimicry for 3D cell culture: a fit-for-purpose investigation from the end user standpoint
}

\begin{abstract}
A plethora of 3D and microfluidics-based culture models have been demonstrated in the recent years with the ultimate aim to facilitate predictive in vitro models for pharmaceutical development. This article summarizes to date the progress in the microfluidics-based tissue culture models, including organ-on-a-chip and vasculature-on-a-chip. Specific focus is placed on addressing the question of what kinds of 3D culture and system complexities are deemed desirable by the biological and biomedical community. This question is addressed through analysis of a research survey to evaluate the potential use of microfluidic cell culture models among the end users. Our results showed a willingness to adopt 3D culture technology among biomedical researchers, although a significant gap still exists between the desired systems and existing 3D culture options. With these results, key challenges and future directions are highlighted.
\end{abstract}

This article summarizes the progress in the development of microfluidics-based 3D cell/tissue culture models to date, including organ-on-a-chip and vasculature-on-a-chip capable of mimicking in vivo tissue architecture. Specific focus is placed on addressing the question of what kinds of 3D culture and system complexities are deemed desirable by the biomedical community. A research survey targeting biomedical researchers was designed to evaluate the potential application of microfluidics-based 3D culture systems and a positive attitude was recorded among its participants.

First draft submitted: 16 November 2016; Accepted for publication: 19 January 2017; Published online: 2 March 2017

Keywords: $3 D$ culture $\bullet$ complexity $\bullet$ microenvironment $\bullet$ microfluidics $\bullet$ organ-on-chip

Human combat against lethal diseases such as cancer and age-related deterioration has long been hampered by a lack of effective, accessible and safe therapies. This can be partly attributed to the inefficiency of current drug development practice [1], especially the low-predictive power of preclinical models [2-4]. Traditionally, drug screening starts in $2 \mathrm{D}$ petri dishes where immortalized human cell lines are cultured in monolayers. Though easy for standardization, the petri dish system is too simplistic and lacks microenvironment complexity and physiological relevance to living tissues. Too often,
2D models produce false positive results, giving unreliable or even misleading predictions for down-stream tests [5]. Physiologically relevant conditions can be found in animalbased systems such as ex vivo chicken chorioallantoic membrane assays, in vivo transgenic mice or mouse xenografts [6]. However, drugs that work well in an animal model often fail when translated in humans $[7,8]$, due to the phylogenetically remote relationship between different species. In addition, animal studies have long been criticized for their high cost, labor-intensiveness, low reproducibility and poor controllability over physiological
Ye Liu', Elisabeth Gill' \& Yan Yan Shery Huang ${ }^{* 1}$ 'Department of Engineering, University of Cambridge, Trumpington Street, Cambridge, UK, CB2 1PZ *Author for correspondence: yysh2@cam.ac.uk 
parameters [9]. All these factors give rise to the emergence of $3 \mathrm{D}$ culture technology, which aims to create a more controllable yet accurate culture platform for preclinical study. Figure 1 summarizes a number of established preclinical models with varying complexity for drug development.

$3 \mathrm{D}$ cell culture, as its name suggests, refers to the in vitro culture of human cell lines or patient-derived tissues in a more physiologically relevant, 3D miniature niche [10]. Recent advances in this field include the design of extracellular matrix (ECM) mimicking hydrogel matrices [11,12] and fiber scaffolds [13,14], microfluidic 'organ-on-a-chip' [15,16], self-assembled multicellular spheroids $[17,18]$ and bioprinted micro tissues $[19,20]$. Table 1 lists some of the key microenvironment cues, and the reported methods to replicate them in $3 \mathrm{D}$ culture models. It is expected that by increasing the structural, chemical and physical complexity of the in vitro culture environment, 3D cell culture will possess great advantages over the conventional $2 \mathrm{D}$ culture and may demonstrate increased predictive power as a next-generation drug testing platform [21]. Moreover, since 3D culture niches accommodate human cells/tissues, they can potentially help bridge the gap between animal studies and human-based clinical trials [22]. With the drive toward drug screening, many of the aforementioned 3D culture designs have been commercialized into scalable multiwell plate format. Table 2 summarizes examples of some of the currently available 3D culture systems, ranging from scaffold-based models such as 3D hydrogels and polymeric membranes to scaffold-free ones such as microfluidics, spheroids and direct-printed mini tissues.

With the rapid development of an extended range of enabling technologies for 3D cell culture, one question desperately needs to be answered: what determines an ideal 3D culture model? We believe at least three criteria should be considered: balanced complexity and userfriendliness, proven functionality and high controllability. First, an in vitro model needs to demonstrate considerable complexity in order to reproduce some of the key attributes of the natural cellular microenvironment. These elements, as summarized in Figure 2, include biomechanical stimuli, extrinsic forces, chemical gradients and cell-cell interactions. However, it is worth mentioning that the choice of the system and complexity always depends on the research question to be addressed. Second, in order to add value to basic science and clinical studies, a 3D culture model should demonstrate its physiological relevance, showcasing its capability to recapitulate key characteristics of in vivo scenarios and key functionalities of tissues/organs. Furthermore, a culture system has to be robust and highly controllable to facilitate standardization, high throughput and commercialization.
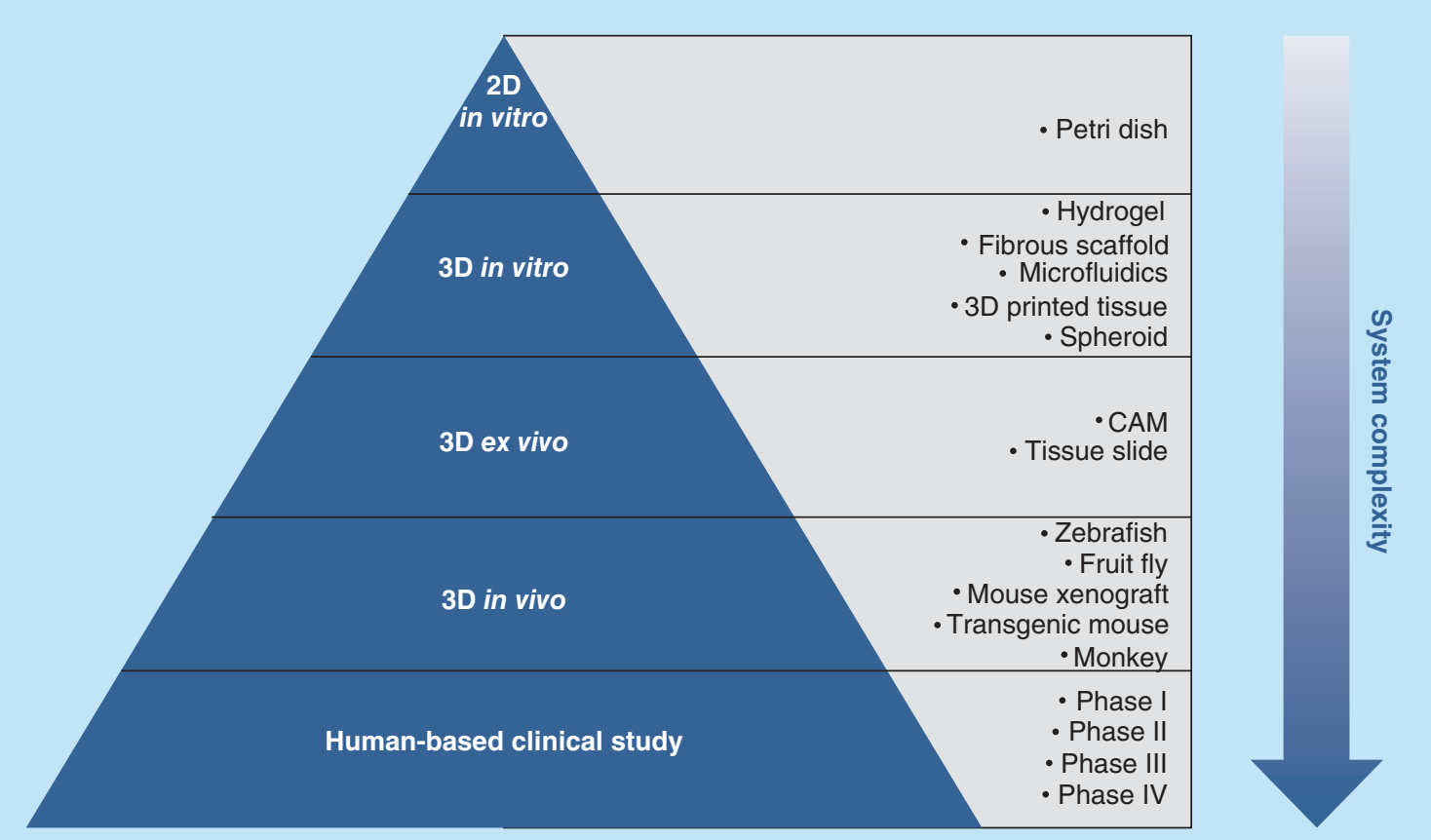

Figure 1. Preclinical and clinical models for drug development. With an increase in system complexity, preclinical models range from 2D petri dish, to 3D in vitro and ex vivo culture systems, to in vivo animal models. Clinical studies are based on human subjects and consist of four testing phases.

CAM: Chicken chorioallantoic membrane assay. 


\begin{tabular}{|c|c|c|c|c|c|c|}
\hline $\begin{array}{l}\text { Biomimetic } \\
\text { microenvironment cues }\end{array}$ & Function & 3D hydrogel & $\begin{array}{l}\text { Polymer } \\
\text { scaffold }\end{array}$ & Microfluidics & Spheroid & 3D printing \\
\hline $\begin{array}{l}\text { Spatial organization of } \\
\text { cells/ECMs }\end{array}$ & Reproduce 3D tissue structure & {$[23,24]$} & {$[25,26]$} & {$[27,28]$} & [29] & {$[30,31]$} \\
\hline Chemical gradient & $\begin{array}{l}\text { Reproduce gradient of signaling } \\
\text { molecules/growth factors }\end{array}$ & {$[32,33]$} & {$[34]$} & {$[35,36]$} & {$[37]$} & - \\
\hline $\begin{array}{l}\text { Coculture of heterotypic } \\
\text { cells }\end{array}$ & Enable cell-cell cross-talk & {$[38,39]$} & {$[40,41]$} & {$[42-44]$} & {$[45,46]$} & {$[47,48]$} \\
\hline External force stimuli & Enable biomechanical sensing & {$[49,50]$} & {$[51,52]$} & {$[53,54]$} & {$[55]$} & {$[56,57]$} \\
\hline ECM & $\begin{array}{l}\text { Reproduce structural, } \\
\text { mechanical and chemical } \\
\text { properties of ECM }\end{array}$ & {$[58,59]$} & {$[60,61]$} & {$[62,63]$} & {$[64,65]$} & {$[66,67]$} \\
\hline Hypoxia & Induce tumor angiogenesis & {$[68]$} & [69] & {$[69-70]$} & {$[64]$} & {$[71]$} \\
\hline Topography & $\begin{array}{l}\text { Direct cell motion and confine } \\
\text { cell distribution }\end{array}$ & {$[72,73]$} & {$[60,61]$} & {$[74,75]$} & {$[76]$} & {$[77,78]$} \\
\hline Simulated body fluids & $\begin{array}{l}\text { Reproduce blood/interstitial } \\
\text { flow }\end{array}$ & - & - & {$[79-81]$} & - & - \\
\hline $\begin{array}{l}\text { Typical microenvironment feature } \\
\text { ECM, hypoxia, topography and b } \\
\text { hydrogel matrix, fibrous polymer } \\
\text { ECM: Extracellular matrix. }\end{array}$ & $\begin{array}{l}\text { nclude spatial organization of cells/ECM, } \\
\text { y fluids. Individual or a combination of } m \\
\text { affold, microfluidics, multicellular sphero }\end{array}$ & $\begin{array}{l}\text { emical gradie } \\
\text { vironment } C \\
3 D \text { printed } t\end{array}$ & $\begin{array}{l}\text {-existe } \\
\text { be re }\end{array}$ & $\begin{array}{l}\text { terotypic cells, } \\
\text { sing various } 3 D\end{array}$ & $\begin{array}{l}\text { ernal mech } \\
\text { ulture metho }\end{array}$ & $\begin{array}{l}\text { ical stimuli, } \\
\text { s such as }\end{array}$ \\
\hline
\end{tabular}

In this article, we will pay specific focus on addressing the question of what kinds of system complexities are deemed desirable by the biological and biomedical community. We first review the microfluidicsbased 3D culture technology for organ-on-chips and in vitro microvascular models. Then we present the results obtained from a questionnaire designed to evaluate the potential use of microfluidic cell culture among biomedical researchers. Key challenges and future direction for microfluidic 3D culture are also highlighted.

\section{On-chip biomimicry}

Microfluidics refers to the manipulation of fluids of small volume (usually less than $10 \mu \mathrm{l}$ ) inside a channel of sub-millimeter scale. At micro scale, various phenomena are prevalent in fluids: laminar flow, improved molecular diffusion and accelerated heat transfer. In the early 1990s when the first microfluidic chips were fabricated in glass or oxidized silicon, they were primarily used in microelectromechanical systems [84] and separation science [85]. Later, microfluidics were introduced to the biomedical community because of their potential to greatly reduce the consumption of expensive reagents and valuable samples. Another attractive attribute of microfluidics is that laminar flow enables the design of physiologically relevant fluidic patterns, chemical gradients and spatially organized cells/ECMs. From the mid-1990s, the concept of on-chip biomimicry of tissues/organs using microfluidics-based miniature chips slowly began to prosper. Among the earliest attempts, Frame et al. designed branching micro tubes $(20-50 \mu \mathrm{m}$ in diameter) etched on a borosilicate microscope slide glass to reproduce the geometry of the arteriolar microcirculation [86]. Endothelial cells were cultured inside the microchannel under perfusion of culture medium for up to $24 \mathrm{~h}$. However, the microfluidic chips made of glass/silicon were brittle, the fabrication procedure was slow and required a clean room facility. Therefore, scientists started to prototype microfluidic chips using a more robust and low-cost elastic polymer called polydimethylsiloxane (PDMS) [87]. This move from glass/silicon to PDMS drastically accelerated the application of microfluidics in biology. PDMS chips are relatively easy to fabricate, and are able to generate statistically analyzable information in parallel operation. Also of critical importance, the optical transparency of PDMS enables real-time imaging, which is desirable for almost all branches of biomedical research. Over the past decade, a myriad of microfluidic designs with complex microarchitecture, significant bioelectrical and biochemical functionality have been realized through the addition of pneumatic valves [88], pillars [89], droplets [90], electrodes [91], hydrogel matrices [92] and electrospun fiber scaffolds [63,93]. Such delicate microfluidics platforms have the potential to be developed for 3D biomimetic tissues and organotypic cultures, for a range of biomedical purposes. One popular example is the micro- 


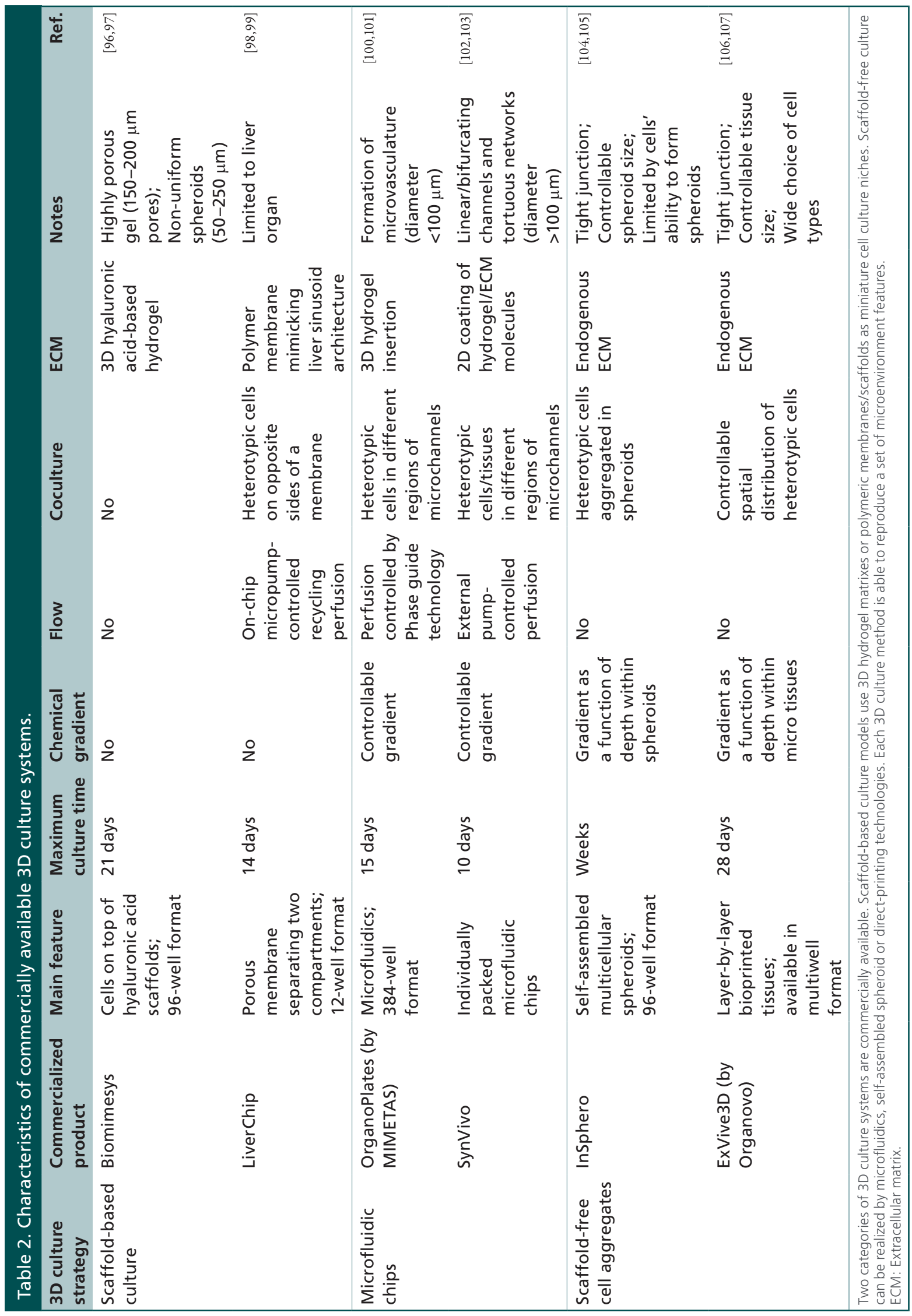




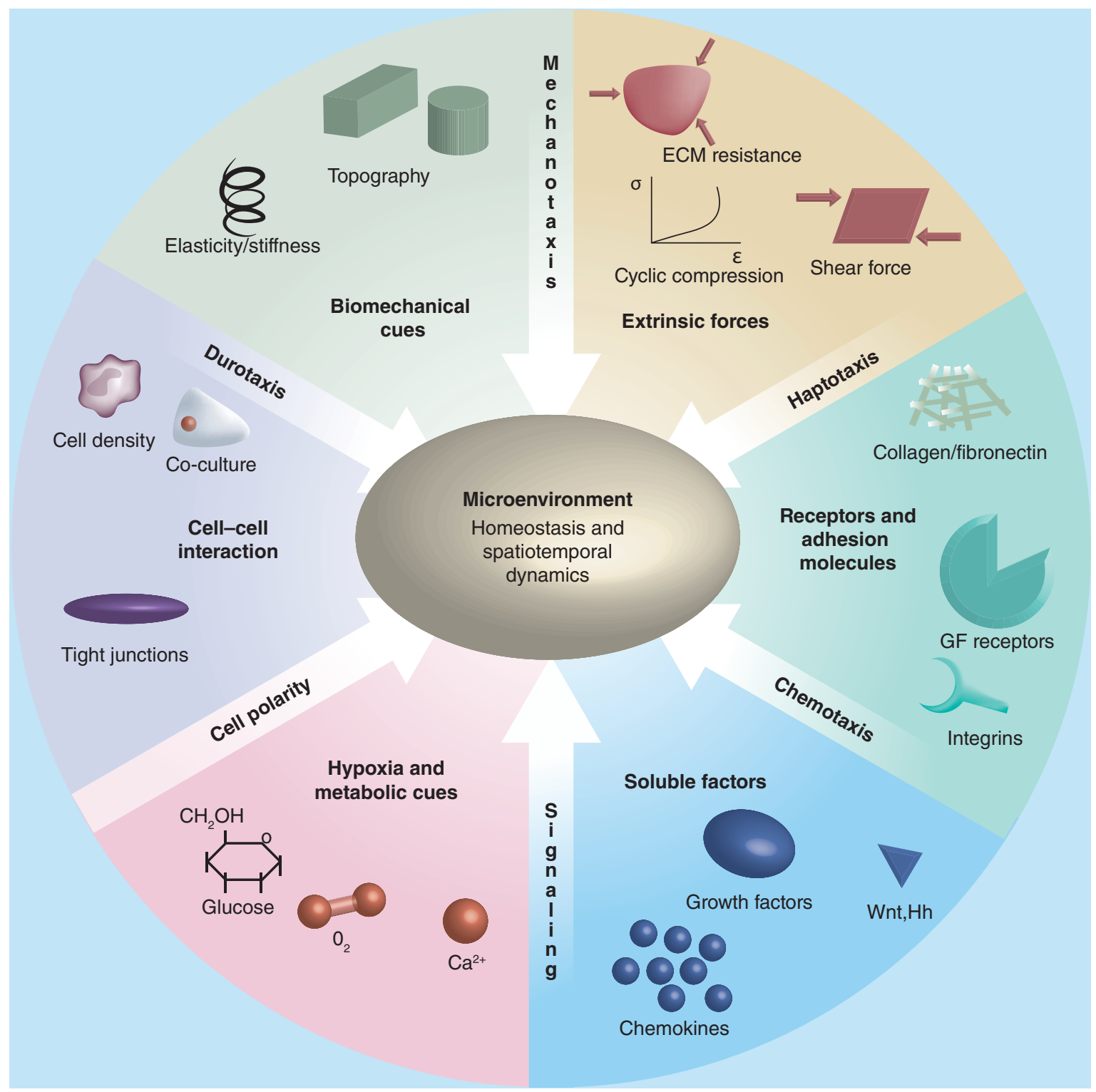

Figure 2. Key microenvironment homeostasis and spatiotemporal dynamics that are desirable to be modeled in in vitro 3D culture systems. All microenvironment cues are dynamic, heterotypic and drivers of cell behavior and fate. ECM: extracellular matrix; GF: growth factor Adapted from $[82,83]$.

fluidic-based organ-on-a-chip systems [94,95], some of which are illustrated in Table 2.

Probably one of the most famous examples of microfluidic organ-on-a-chip is the lung-on-a-chip realized by Huh et al. to mimic pulmonary edema [53]. Briefly, an upper air channel was separated from a lower liquid channel by a porous PDMS membrane, the opposite sides of which formed epithelium and endothelium layers respectively. Two side channels parallel to the central channels were connected to a vacuum pump that cyclically mimicked the breathing motion of the lung. This lung-on-a-chip is a hallmark achievement in organ-on-chip development and has inspired the development of other human organ chips such as the gut-on-a-chip [108], kidney on-a-chip [109] and placenta on-a-chip [62]. More complex microsystems have also been created for the 'human-on-a-chip', in which various organ equivalents are integrated into one single chip. For example, a four-organ-chip was established by Maschmeyer et al., demonstrating long-term coculture of liver spheroids, an intestine barrier insert, a skin biopsy insert and a polymeric kidney membrane. The four biomimetic organs were interconnected through a microfluidic circulation system perfused with surrogate blood [110]. Such a multi-organ platform can be used to observe the systemic responses of intercom- 
municating organs during complex physiological and pathophysiological processes including food metabolism and pharmacokinetics. Apart from culturing human organ-specific cell lines in microfluidic chips, other cell and tissue sources such as human tissue slides and pluripotent stem cells have also been reported. For instance, organotypic culture of brain slices for up to 40 days were performed in a microfluidic system which enabled the compartmentalization of different functional units of the brain as well as easy manipulation of selected neural circuits [111]. Stem cell culture using microfluidics was also demonstrated in a study on ECM-mediated neural stem cell differentiation [112]. Finally, it is worth mentioning that the microenvironmental cues for these biopsy-derived tissues or selforganizing stem cells have to be well understood and carefully designed to ensure long-term culture as well as well-controlled cell fate [113].

\section{Microfluidic vasculature models}

Aside from microfluidic organ-on-a-chips, another key focus of tissue engineers is blood vessels and capillaries, which are the basic building blocks of almost all organs and many important tissue structures such as the bloodbrain barrier [114], lung alveoli [115] and renal glomerulus [116]. Vasculature enables gas exchange in the body as well as the transport of nutrients, waste, pathogens, blood cells and circulating cancer cells. Lack of proper vascularization can induce the formation of necrotic cores [117], which has been a common problem in many large-scale tissue constructs. Of equal importance, vascular endothelial cells are active in many signaling events such as hypoxia-initiated angiogenesis [118], stem cell differentiation [119] and the insulin signaling pathway [120]. Many cell-cell interactions that take place in vivo, including leukocyte-endothelium [121] and platelet-endothelium interaction [122], also involve the active participation of vascular endothelial cells. Vasculature is indispensable in modeling any process that is circulation driven such as inflammatory responses [123], cardiovascular diseases [124], cancer intravasation [125] and extravasation [126]. Therefore, creating 3D in vivolike vasculature has always been an important research question in the engineering of tissue surrogates and disease-on-a-chip.

Thanks to the many advantages microfluidics possess, tissue engineers have been employing microfluidics technology to mimic vasculature networks over the past two decades $[127,128]$. First, microfluidic channels, from a few to hundreds of microns in diameter, are a convenient tool to mimic the geometry of microcirculation. Second, flow in microfluidic devices can be tailored to recapitulate the dynamic and fluidic microenvironment that cells experience in vivo including body fluids (blood and interstitial fluids), shear stress and mass transportation. One successful example is an endothelialized microvasculature developed by Tsai et al., with branching channels (smallest diameter of $30 \mu \mathrm{m}$ ) emulating a postcapillary venule. Using this hemodynamics-mimicking platform, they studied the effect of an inflammatory cytokine TNF- $\alpha$ and the drug hydroxyurea on microvascular obstruction under perfusion of patient blood [129]. Apart from the simulation of vasculature anatomy and hemodynamics, spatiotemporally defined chemical gradients are also achievable in microfluidic devices by manipulating liquids of different chemical concentrations in parallel channels. Third, heterotypic cells can be subsequently seeded and cocultured in the same microfluidic chip. Such coculture capability offers significant convenience for researchers interested in cell-cell interactions [130] happening in tumor-immune response [131] and vasculogenesis [132]. To summarize, microfluidics provide unique microenvironmental attributes such as lumen architecture, flow and spatial distribution of cells/particles that are difficult to define using other $3 \mathrm{D}$ culture technologies. Therefore, microfluidics represent a powerful tool in mimicking tissue structures requiring the presence of vascular networks.

Over the decade, various techniques have been established to pattern microfluidic networks for vasculature generation. Table 3 summarizes the development of several microfluidic vasculature models. The most common and well established fabrication method is photolithographic moulding of PDMS. Microvessels of rectangular cross-section can be easily fabricated to be later populated by human vascular endothelial cells [133]. However, the diameter of these microvessels is limited by the resolution of soft lithography. Most microvessels patterned via soft lithography are able to mimic arteries and veins of more than $100 \mu \mathrm{m}$ in diameter $[42,89,134]$, but are far from reaching the geometry of very fine capillaries $(10-20 \mu \mathrm{m})$ [135]. In addition, most of the lithography-moulded microvessels are made of synthetic polymers including PDMS and are lined with a single layer of vascular endothelial cells. Such synthetic and monolayer structures are unable to mimic the natural architecture of blood vessel walls, which usually consist of stacked layers of endothelial cells, a basement membrane, pericytes, smooth muscle cells and fibroblasts. These stromal layers outside vascular endothelium are known to be very important for endothelial junction performance $[136,137]$. To mimic the stroma surrounding blood vessels, alternative techniques such as injection moulding have been developed to pattern vasculature inside ECM hydrogels. For instance, Baker et al. injection-moulded gelatin, a natural thermoplastic protein, into a microvascula- 
ture construct and embedded it within collagen hydrogel [35]. The gelatin was then melted at $37^{\circ} \mathrm{C}$ and left open channels inside the collagen gel. The vasculature reached a diameter of less than $100 \mu \mathrm{m}$ and the crosssection was quasi-cylindrical. A similar strategy was developed in the same group, where 3D printed lattices made of sacrificial carbohydrate glass were used to pattern vasculature inside ECM [138]. The glass lattices were encapsulated within various ECM materials along with living cells and later dissolved in cell media to create perfusable vascular networks. These microvessels had cylindrical lumen and a minimum diameter of around $200 \mu \mathrm{m}$. It is worth mentioning that compared with lithography-moulded planar microchannels, such cylindrical lumen closely mimics the anatomy and hemodynamics of real blood vessels [139]. Alternatively, viscous finger patterning [140], removable nitinol rods [141] and laser beams [142] were also used to pattern cylindrical microchannels inside ECM gels. For example, Hasan et al. inserted concentric needles of varying diameters into a microchannel and subsequently loaded cell laden gelatin methacryloyl (GelMA) hydrogel into the annular interneedle space. The use of concentric needles was to create multilayered cylindrical vascular walls consisting of endothelial, smooth muscle and fibroblast layers [143]. A much easier approach to create 'do-it-yourself' endothelialized microfluidics was also reported in which researchers used removable polymethylmethacrylate optical fibers to pattern vasculature for the study of endothelial-blood cell interaction [144].

Using these aforementioned microfluidic fabrication methods, microchannel networks in the hundreds of micron scale can be patterned within synthetic or natural polymeric materials and be lined with vascular endothelial cells. This microvessel generation technique can be termed as 'prevascularization technique' [145]. However, to replicate the complex networks of fine capillaries, angiogenesis-assisted vascularization is a more appropriate strategy. Briefly, vascular endothelial cells are seeded inside ECM hydrogels with angiogenic stimuli such as shear stress and vascular endothelial growth factor (VEGF) [130], and are cultured for days to form spontaneously interconnected capillary networks. The main limitation of the angiogenesis technique is that the system often requires a set of predefined culture conditions, which restrict system tunability and hemodynamic controllability. Table 4 crosscompares the two vascularization approaches. It is of note that individual [43] or combined [146] strategies can be employed to address various research questions. To improve physiological relevance, important directions for the future development of biomimetic vasculature include: improving coculture complexity, refining vasculature dimension and enhancing fluidic control. Another issue is system validation. Although microfluidic microvasculature systems possess great potential for studies on hemodynamics and endothelial-blood

Table 3. Characteristics of microfluidic vasculature generation technologies.

\begin{tabular}{|c|c|c|c|c|c|}
\hline $\begin{array}{l}\text { Microfluidic vasculature } \\
\text { generation technology }\end{array}$ & Cross-section & Geometry & Note & Advantages & Ref. \\
\hline $\begin{array}{l}\text { Photolithographic } \\
\text { moulding }\end{array}$ & Planar & $>30 \mu \mathrm{m}$ & $\begin{array}{l}\text { Most developed } \\
\text { and standardized } \\
\text { technology }\end{array}$ & $\begin{array}{l}\text { Fluid } \\
\text { Chemical gradient } \\
\text { Coculture }\end{array}$ & {$[42]$} \\
\hline Injection moulding & $\begin{array}{l}\text { Quasi- } \\
\text { cylindrical }\end{array}$ & $>20 \mu \mathrm{m}$ & $\begin{array}{l}\text { Template molded in } \\
\text { sacrificial material }\end{array}$ & $\begin{array}{l}\text { Fluid } \\
\text { Chemical gradient } \\
\text { Coculture }\end{array}$ & [35] \\
\hline Direct-write assembly & Cylindrical & $200-800 \mu \mathrm{m}$ & $\begin{array}{l}\text { Template direct- } \\
\text { printed from } \\
\text { sacrificial material }\end{array}$ & $\begin{array}{l}\text { Fluid } \\
\text { Chemical gradient } \\
\text { Coculture }\end{array}$ & {$[138]$} \\
\hline Viscous finger patterning & Cylindrical & $100-700 \mu \mathrm{m}$ & $\begin{array}{l}\text { Less controllable } \\
\text { vessel geometry }\end{array}$ & $\begin{array}{l}\text { Fluid } \\
\text { Chemical gradient } \\
\text { Coculture }\end{array}$ & {$[140]$} \\
\hline Removable rods & Cylindrical & $150 \mu \mathrm{m}$ & $\begin{array}{l}\text { Stiff hydrogel to } \\
\text { withstand rod } \\
\text { removal }\end{array}$ & $\begin{array}{l}\text { Fluid } \\
\text { Chemical gradient } \\
\text { Coculture }\end{array}$ & {$[141]$} \\
\hline Laser micromachining & Cylindrical & $8 \mu \mathrm{m}$ & $\begin{array}{l}\text { Precise control over } \\
\text { small geometry }\end{array}$ & $\begin{array}{l}\text { Fluid } \\
\text { Chemical gradient } \\
\text { Coculture }\end{array}$ & {$[142]$} \\
\hline
\end{tabular}


Table 4. Principle, advantages and disadvantages of two vasculature generation strategies.

\begin{tabular}{|c|c|c|c|}
\hline $\begin{array}{l}\text { Vasculature generation } \\
\text { strategy }\end{array}$ & Principle & Advantages & Disadvantages \\
\hline Prevascularization & $\begin{array}{l}\text { Endothelial lining of } \\
\text { predefined vasculature }\end{array}$ & $\begin{array}{l}\text { Precise control over } \\
\text { vasculature architecture } \\
\text { Precise control over flow }\end{array}$ & $\begin{array}{l}\text { Simple geometry } \\
\text { Low resolution }\end{array}$ \\
\hline $\begin{array}{l}\text { Angiogenesis-assisted } \\
\text { vascularization }\end{array}$ & $\begin{array}{l}\text { Chemical-induced } \\
\text { angiogenesis in } \\
\text { endothelial-embedded } \\
\text { hydrogel }\end{array}$ & $\begin{array}{l}\text { Complex geometry, } \\
\text { dense network } \\
\text { Cylindrical lumen } \\
\text { Self-organized capillaries }\end{array}$ & $\begin{array}{l}\text { Limited to tumor } \\
\text { vasculogenesis } \\
\text { Low controllability over } \\
\text { flow } \\
\text { Slow formation of } \\
\text { vasculature }\end{array}$ \\
\hline
\end{tabular}

cell interaction, very few of these devices have been directly validated against in vivo models. More crosssystem comparisons need to be completed to encourage wide applications of vasculature-on-chip.

\section{Desirable culture features: a research survey analysis from the end user standpoint}

Although a plethora of microfluidic-based culture models has been developed, as described above, the adaptation of these models to address biologically focused research questions is sparse. Among the biological community, which is the intended end user of 3D culture systems, a sceptical attitude still exists: potential customers are concerned about the reliability, functionality and reproducibility of engineered tissues. To better appreciate the expectations and concerns of biomedical researchers, we designed a comprehensive survey to assess the acceptance of $3 \mathrm{D}$ in vitro culture systems, focused on microfluidics. The questionnaire is shown as Supplementary Data 1. It includes 12 single choice questions investigating researchers' background and acceptability of 3D culture models, five multiple choice questions on their preferences and suggestions, and one open question on the signaling pathways they are interested in. We invited via email 70 bioscience researchers from academia and the pharmaceutical industry, to participate in the survey. The participants were not filtered by their familiarity of the authors or by certain research fields. Among the invited participants, 46 were worldrenowned bioscientists who have published highly cited articles (from 2006 to date) in 15 top bioscience journals such as Nature Biotechnology, Journal of Cell Biology, Cell and Nature Reviews Molecular Cell Biology. Another 24 lab-based biomedical researchers including $\mathrm{PhD}$ students and early-career Postdocs (mainly based in the University of Cambridge) were also involved in the survey.
In total, 42 researchers completed the questionnaire which translates to a response rate of $60 \%$. The participants contain a combination of 15 research group leaders, 24 lab-based researchers and three industrial scientists (see Figure 3A). Their research covers areas including cancer, neuroscience, stem cell, toxicology, endocrinology and aging. Signaling molecules and pathways such as p53, Rho GTPases, integrin, EGFRs, ROS, WNT, IR, HIF-1 are indicated as a subject of interest. Further, major analytical tools used by these researchers were investigated to identify which type of downstream assays a culture system should be able to adapt to. The data revealed that typical analytical methods employed by biomedical researchers include western blotting, polymerase chain reaction (PCR), immunefluorescent microscopy, live cell imaging and flow cytometry (Figure 3D). When it comes to the usage of $3 \mathrm{D}$ culture systems such as microfluidic chips, the majority of the researchers did not have previous experience. One out of five used microfluidics occasionally and only $7.1 \%$ were familiar with this technique (Figure 3B). However, $85.7 \%$ (36 out of 42) of the researchers expressed a clear interest in adopting microfluidic culture in their research, either performed by themselves $(50 \%)$ or by collaborators (35.7\%) such as a provider company or a collaborative research group (Figure $3 \mathrm{C}$ ). When queried about key obstacles that may prevent the uptake of new cell culture technologies, researchers listed five major concerns as system reproducibility, standardization, validation, ease of use and compatibility with analytical assays (Figure 3E), which should be overcome by future 3D models. However, we would like the reader to note that due to the relatively small size of the cohort, there is a possibility that this study may not capture all the opinions of researchers from the different fields. 
As aforementioned, an ideal 3D culture model should demonstrate considerable microenvironment complexity to achieve a close resemblance to natural tissues. Therefore, details of desirable microenvironment features determined by biomedical researchers were summarized in Supplementary Figure 1. We classified two subgroups in the cohort: the 'advanced-career researchers (ACR)' group (18 out of 42), referring to scientists who have more than 7 years of research experience in their fields; and the 'early-career researchers (ECR)' (24 out of 42), referring to researchers with less than 7 years of experience. This classification is for the purpose of generating a detailed observation on the preference of scholars within these two groups.
In total, eight microenvironment factors were evaluated and the importance of each factor was weighed using a scoring scale of $0-4$ (Supplementary Figure 1A), where 0 was classified as 'not important at all', and 4 as 'absolutely essential'. The data suggested that both subgroups agree on the importance of the spatial organization of cells/ECM in a 3D culture system; whereas varying views were recorded for the remaining seven features. For instance, $88.88 \%$ of the 'ACR' group scored above 3 ('very important' to 'absolutely essential') for the 'coculture' factor, while only $50 \%$ of the 'ECR' group expressed such a strong preference. This difference reflected a variance in researchers' actual need and expectation for new culture models, which

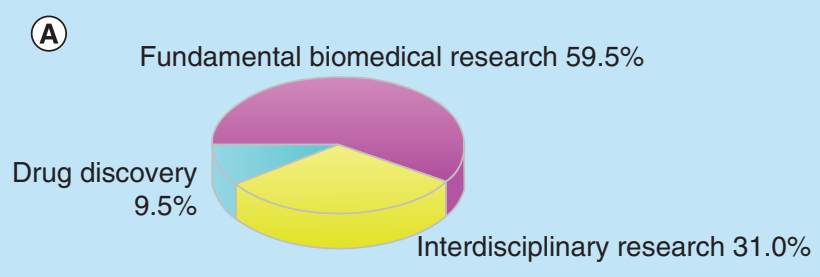

Characterization of research

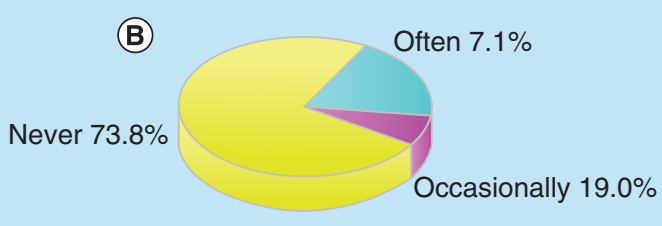

Usage of microfluidics

(D)

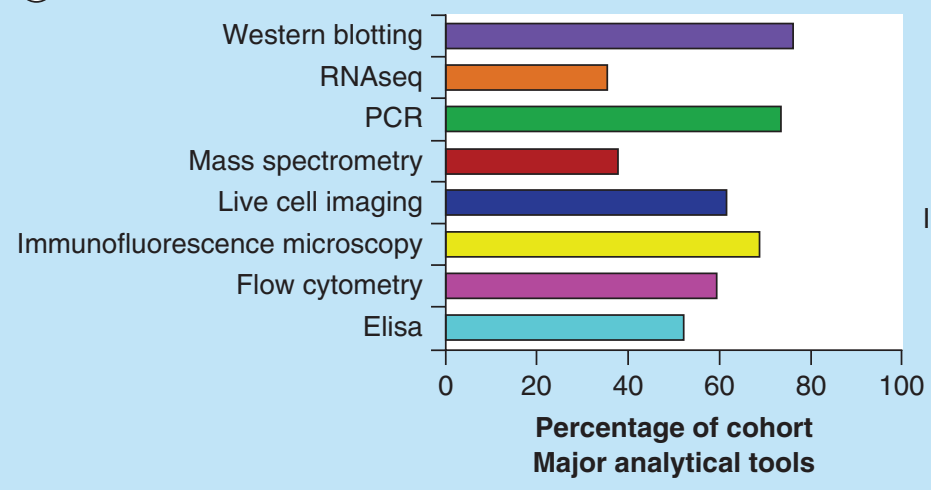

(C)

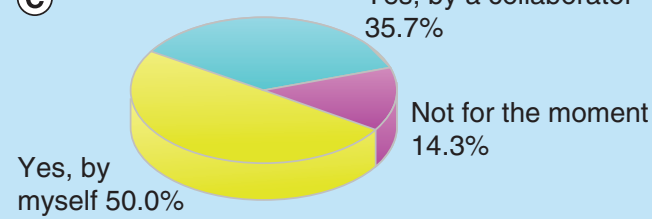

Acceptability of microfluidics

(E)

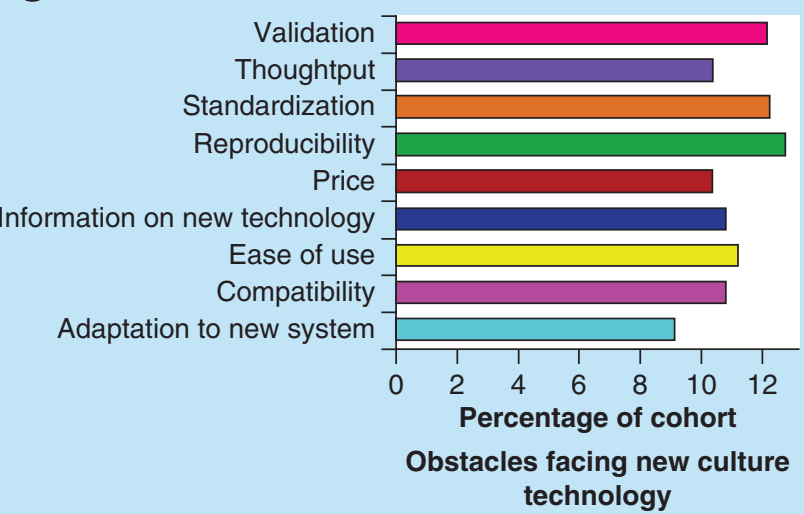

Figure 3. Characterization of research area, usage and acceptability of microfluidic culture systems, usage of analytical tools and concerns about new culture technology among biomedical researchers. (A) The cohort consists of scientists from fundamental, interdisciplinary research and drug discovery industry. (B) Few researchers have previous experience of using complex 3D culture models including microfluidics. (C) Acceptance of 3D culture systems including microfluidics is a predominant response. (D) Popular analytical tools for biomedical scientists include western blotting, PCR, immunofluorescence microscopy, live cell imaging, flow cytometry and ELISA. (E) Potential users are concerned about the reproducibility, standardization, validation, user-friendliness and compatibility of new culture technology.

PCR: Polymerase chain reaction. 
may influence their final decision making as well as the design priority and marketing strategy of $3 \mathrm{D}$ culture developers. The average weight of each microenvironment factor was listed in Supplementary Figure 1B, with spatial organization, coculture and ECM ranked as essential characteristics (scored around or above 3), while external force stimuli, topography, fluids, hypoxia and chemical gradient as desirable features (scored between 2 and 3).

Further details of researchers' preference on other 3D culture characteristics were shown in Figure 4. The two subgroups have varying views on the choice of coculture number, ECM, product type and price. For instance, half of the 'ACR' group desired a complex system that is able to coculture at least four types of cells, while a greater percentage $(60 \%)$ of the 'ECR' expected a simpler system enabling only two types of cells in coculture (Figure 4A). As for the preferred method to incorporate ECM, a majority of the 'ACR' group opted for 3D fibrous scaffolds, hydrogel matrices and endogenous ECM, while half of the 'ECR' favored a simpler, 2D thin coating of ECM components (Figure 4B). Similarly, the 'ACR' preferred more customized, complex systems and were willing to pay up to three-times higher prices. By contrast, the other group showed greater interest in standardized models and expected lower prices (Figure $4 C \& D$ ). In summary, 'ACR' have higher expectations for the complexity, physiological relevance of a 3D culture system and expressed clear interest in customizable products. This variance in researchers' decision making, even sometimes subtle, should be considered in the design and marketing of 3D culture systems.

With researchers' high expectation for 3D culture in mind, it is worth mentioning that the time and effort needed for system installation often increases with system complexity, as does the end user input and system variability. Therefore, it is important to assess researchers' requirement on the installation, usage and performance of 3D culture systems. Our data revealed that $61.9 \%$ (26 out of 42 ) of the researchers would like to see the completion of the preliminary training and setting up of a 3D culture platform within 4 weeks (Supplementary Figure 2A). Approximately half of the cohort expected similar or higher success rate in the new systems, in comparison to the traditional $2 \mathrm{D}$ systems. However, this expectation is currently difficult to achieve because 3D culture has not yet entered its maturity stage. For instance, many of the complex 3D culture models often fail to reach expected levels of robustness and reproducibility. With this in mind, $28.6 \%$ of the cohort accepted a $20 \%$ decrease in success rate and $21.4 \%$ accepted a $50 \%$ decrease (Supplementary Figure 2B). As to the preparation time, more than one-third of the researchers expected to have a 3D culture device made within 3 days, while a greater percentage (45.2\%, 19 out of 42) are willing to wait for 4-7 days (Supplementary Figure 2C). Also, it can be concluded that depending on the research purpose, the required time that cells be maintained in a 3D culture device varies from days to weeks (Supplementary Figure 2D).

Overall, willingness to adopt 3D culture was the prominent response among biomedical researchers. Key microenvironment features desired by researchers are spatial organization, ECM and coculture of heterotypic cells. Other desirable factors, depending on the research question to address, include external force stimuli, topography, simulated body fluids, hypoxia and chemical gradients. These results resonate with experts' opinions expressed in other reviews on 3D culture [147-150]. In addition, we observed slight variance in the decision making of end users in that 'ACR' opted for 3D models with higher coculture ability, closer physiological relevance and were willing to pay higher prices for customized models. Despite this positive attitude, our survey implied that there still exists a significant gap between the model complexity demanded by especially the ACR, and the capability demonstrated in existing culture systems (as summarized in the previous sections). Although current microfluidic chips, including some commercialized ones such as OrganoPlates, offer a convenient system that to some extent mimics in vivo conditions, few studies using these culture models have been published in leading journals in fundamental biomedical research or pharmaceutical science. Most engineered culture systems are able to demonstrate spatial organization in their biomimetic architectures but lack comprehensive downstream physiological or pharmacological analysis that can fully validate their functionality. Some exceptions do exist, as illustrated in the recent work by Soroush et al., in which a microfluidic vascular network based on in vivo images revealed a key role of protein kinase $C \delta$ in neutrophil transendothelial migration [79]. However, a more 'killer application' may need to be showcased to stimulate a broader uptake of 3D culture models. We believe that achieving a critical set of 'baseline' complexity desired by the biomedical researchers, simultaneously with improved system reproducibility, functionality and user friendliness are the critical stepping stones toward the broader adoption of $3 \mathrm{D}$ culture technologies. Otherwise, there is not a strong enough incentive for the biological community to modify their culture protocols and invest in a new, nonstandardized platform. This hesitation may be a hurdle for new culture systems to be accepted as valuable tools for funda- 
(A)

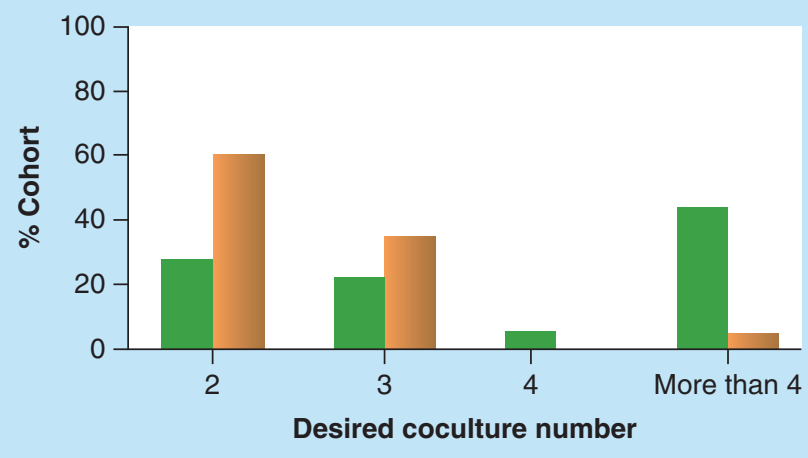

(C)

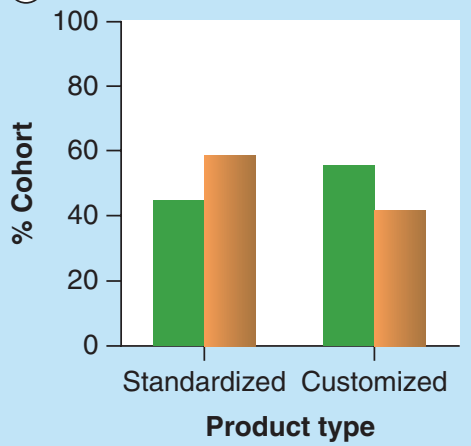

(B)
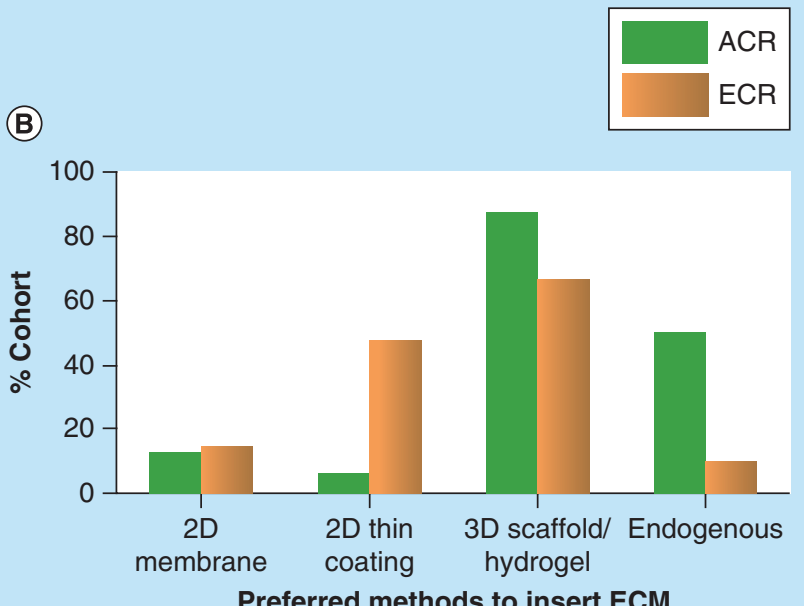

Preferred methods to insert ECM

(D)

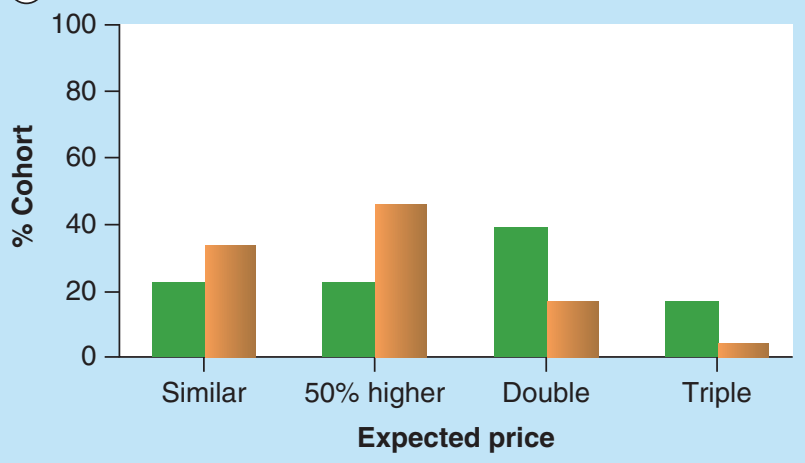

Figure 4. Coculture number, extracellular matrix, product type and price expected by researchers. (A) ACR prefer complex 3D culture systems enabling the coculture of more than four types of cells. ECR require two or three cell types in coculture. (B) ACR prefer 3D scaffold/hydrogel and endogenous ECM. ECR prefer thin coating of ECM molecules and 3D scaffold/hydrogel. (C) ACR prefer more customized culture systems. ECR require standardized products. (D) ACR are willing to pay double or even triple price for 3D culture models. ECR will pay less.

ACR: Advanced-career researcher; ECM: Extracellular matrix; ECR: Early-career researcher.

mental biomedical research and drug screening in an industrial context.

\section{Conclusion}

The versatile functionality and excellent spatiotemporal control over microenvironmental elements in 3D cell culture opens up wide possibilities for tissue engineering and next generation drug testing. Specifically, the ability of microfluidics to biomimic the fluidic in vivo microenvironment and micron-scale luminal structures can be a powerful tool in the creation of organ/vasculatureon-chips. According to our research questionnaire, willingness to adopt 3D culture technology was a prominent response among biomedical researchers, although a significant gap still exists between the desired systems and existing 3D culture options. The survey may provide academic insight for entrepreneurs who are interested in the commercialization of microfluidic-based 3D culture systems.

\section{Future perspective}

The past two decades have seen the emergence and rapid growth of microfluidics-based $3 \mathrm{D}$ culture technology, with the ultimate aim to boost the development of fundamental bioscience and pharmaceutics. A plethora of interesting microfluidic models have been engineered, such as the biomimetic organ- and vasculature-on-a-chip. Despite the many advantages microfluidics offer, they are not without weaknesses. The miniaturization empowered by microfluidics also implies that accessible cells/tissues in the culture system can be too few to be further studied using conventional analytical tools, such as western blotting, ELISA and mass spectrometry. Although some on-chip assays including single-cell PCR [151] and western blotting [152] have been developed for the small sample input from microfluidics, samples in current biomimetic chips are mostly studied using $2 \mathrm{D} / 3 \mathrm{D}$ imaging techniques including epifluorescence and confocal microscopy. 
However, the wide adaptation of microfluidics-based culture methods requires that the systems be validated from a multidimensional angle, by various analytical tools. Therefore, either the culture models should be designed more compatible with existing analytical methods, or more sensitive, advanced analytical/imaging tools have to be developed for or even integrated in microfluidic chips [153]. In addition, most microfluidic systems, compared with the conventional petri dishes, are far less user friendly. Although standardized protocols are now available [42,154], microfluidic systems are still labor-intensive to fabricate and complex to operate. For example, microfluidics often require specific training on the pipetting/coating techniques as well as complicated external setups such as syringe pumps. It is therefore desirable but still challenging that future microfluidics incorporate intelligent on-chip control of oxygen/medium perfusion, while user operation is simplified at the same time.

Though creating a fully functional artificial organ may seem too ambitious, tissue engineers could work toward achieving a decent level of complexity, both structurally and functionally, and from micro to nano scale, in one biomimetic culture system. To realize more physiologically relevant tissue architecture and microenvironment dynamics, microfluidics should explore new fabrication materials beyond PDMS [155], and be combined with other bioengineering tools such as nano-fibrous scaffolds, biosensors and $3 \mathrm{D}$ printing [156]. However, for tissue engineering scientists, developing cutting-edge technology for $3 \mathrm{D}$ culture is no longer the only focus. The bioengineering community should reach out proactively to their biomedical end users, to seek their mutual interests, finding design inspiration from their feedback.

Encouragingly, our research survey revealed that a positive attitude toward 3D culture prevails among biomedical scientists and pharmaceutical researchers. In fact, the past decade saw many encouraging attempts to apply $3 \mathrm{D}$ culture in areas such as cancer metastasis research [157-159] and early-phase drug screening [160]. For instance, a microfluidic device with interconnected chambers housing liver, tumor and marrow cells was used to test the metabolism-dependent cytotoxicity of an anticancer drug, Tegafur [161]. Other applications of microfluidic culture can be found in neuroscience, for purposes of complementing in vivo studies on neuro- nal signaling [162] and high throughput evaluation of neurotoxic compounds [100]. These examples showed how microfluidics-based culture systems can help to bridge the gap between in vitro and in vivo study. As such, we believe that a lot more exciting research with impactful clinical effect can be performed when 3D culture systems are employed in broader areas. For instance, microfluidics-based 3D culture can be further applied for the culture of patient-derived biopsy, for the purpose of developing personalized therapy. Microfluidics also represents a desirable tool to help test our understanding on human stem cell niches, organ development and regenerative medicine. However, in order to become a widely accepted tool in fundamental bioscience and pharmaceutical industry, 3D culture models have to find suitable research questions to address and impart tailored complexity, while overcoming drawbacks such as poor compatibility, relatively low throughput, limited functionality and lack of a standardized metric in cross-system comparison.

\section{Supplementary data}

To view the supplementary data that accompany this paper please visit the journal website at: www.future-science.com/ doi/full/10.4115/fsoa-2016-0084

\section{Acknowledgements}

The authors greatly appreciate the opinions and helps given by all the participants in this research survey.

\section{Financial \& competing interests disclosure}

This work has been supported by The Engineering and Physical Sciences Research Council (EPSRC) UK under the grant number EP/M018989/1, and a Royal Society Research Grant. Y Liu received a studentship from the Schlumberger Foundation, and E Gill received a scholarship from the WD Armstrong Trust. The authors have no other relevant affiliations or financial involvement with any organization or entity with a financial interest in or financial conflict with the subject matter or materials discussed in the manuscript apart from those disclosed.

No writing assistance was utilized in the production of this manuscript.

\section{Open access}

This work is licensed under the Creative Commons Attribution 4.0 License. To view a copy of this license, visit http://creativecommons.org/licenses/by/4.0/

\section{Executive summary}

- An ideal 3D culture system should demonstrate a balance of complexity, user-friendliness, physiological relevance and controllability.

- Microfluidics is a valuable tool for the development of organ- and vasculature-on-a-chip.

- Willingness to adopt 3D culture technology was a prominent response among biomedical researchers, although a significant gap still exists between the desired systems and existing 3D culture options. 


\section{References}

Papers of special note have been highlighted as:

- of interest

1 Hay M, Thomas DW, Craighead JL, Economides C, Rosenthal J. Clinical development success rates for investigational drugs. Nat. Biotech. 32(1), 40-51 (2014).

2 Begley CG, Ellis LM. Drug development: raise standards for preclinical cancer research. Nature 483(7391), 531-533 (2012).

3 Prinz F, Schlange T, Asadullah K. Believe it or not: how much can we rely on published data on potential drug targets? Nat. Rev. Drug Discov. 10(9), 712 (2011).

4 Hess KR. Statistical design considerations in animal studies published recently in cancer research. Cancer Res. 71(2), 625 (2011).

5 Abbott A. Cell culture: biology's new dimension. Nature 424(6951), 870-872 (2003).

6 Ruggeri BA, Camp F, Miknyoczki S. Animal models of disease: pre-clinical animal models of cancer and their applications and utility in drug discovery. Biochem. Pharmacol. 87(1), 150-161 (2014).

7 Perrin S. Preclinical research: make mouse studies work. Nature 507(7493), 423-425 (2014).

8 Reagan-Shaw S, Nihal M, Ahmad N. Dose translation from animal to human studies revisited. FASEB J. 22(3), 659-661 (2008).

9 Kilkenny C, Parsons N, Kadyszewski E et al. Survey of the quality of experimental design, statistical analysis and reporting of research using animals. PLoS ONE 4(11), e7824 (2009).

10 Justice BA, Badr NA, Felder RA. 3D cell culture opens new dimensions in cell-based assays. Drug Discov. Today 14(1), 102-107 (2009).

11 Aubin H, Nichol JW, Hutson CB et al. Directed 3D cell alignment and elongation in microengineered hydrogels. Biomaterials 31(27), 6941-6951 (2010).

12 Tibbitt MW, Anseth KS. Hydrogels as extracellular matrix mimics for 3D cell culture. Biotechnol. Bioeng. 103(4), 655-663 (2009).

13 Heydarkhan-Hagvall S, Schenke-Layland K, Dhanasopon AP et al. Three-dimensional electrospun ECM-based hybrid scaffolds for cardiovascular tissue engineering. Biomaterials 29(19), 2907-2914 (2008).

14 Coburn J, Gibson M, Bandalini PA et al. Biomimetics of the extracellular matrix: an integrated three-dimensional fiberhydrogel composite for cartilage tissue engineering. Smart Struct. Syst. 7(3), 213-222 (2011).

15 Dittrich PS, Manz A. Lab-on-a-chip: microfluidics in drug discovery. Nat. Rev. Drug Discov. 5(3), 210-218 (2006).

- Discusses applications and potential of microfluidics for drug discovery.

16 Huh D, Torisawa Y, Hamilton GA, Kim HJ, Ingber DE. Microengineered physiological biomimicry: organs-on-chips. Lab Chip 12(12), 2156-2164 (2012).

17 Kang J, Lee DW, Hwang HJ, Yeon S-E, Lee M-Y, Kuh H-J. Mini-pillar array for hydrogel-supported 3D culture and high-content histologic analysis of human tumor spheroids. Lab Chip 16(12), 2265-2276 (2016).

18 Tung Y-C, Hsiao AY, Allen SG, Torisawa Y, Ho M, Takayama S. High throughput 3D spheroid culture and drug testing using a 384 hanging drop array. Analyst 136(3), 473-478 (2011).

19 Murphy SV, Atala A. 3D bioprinting of tissues and organs. Nat. Biotech. 32(8), 773-785 (2014).

20 Norotte C, Marga FS, Niklason LE, Forgacs G. Scaffoldfree vascular tissue engineering using bioprinting. Biomaterials 30 (30), 5910-5917 (2009).

21 Breslin S, O'Driscoll L. Three-dimensional cell culture: the missing link in drug discovery. Drug Discov. Today 18(5-6), 240-249 (2013).

22 Pampaloni F, Reynaud EG, Stelzer EHK. The third dimension bridges the gap between cell culture and live tissue. Nat. Rev. Mol. Cell Biol. 8(10), 839-845 (2007).

- Important article on 3D cell culture.

23 Ramón-Azcón J, Ahadian S, Obregón R et al. Gelatin methacrylate as a promising hydrogel for 3D microscale organization and proliferation of dielectrophoretically patterned cells. Lab Chip 12(16), 2959-2969 (2012).

24 Pietrzyk-Nivau A, Poirault-Chassac S, Gandrille S et al. Three-dimensional environment sustains hematopoietic stem cell differentiation into platelet-producing megakaryocytes. PLoS ONE 10(8), e0136652 (2015).

25 Horst M, Madduri S, Milleret V, Sulser T, Gobet R, Eberli D. A bilayered hybrid microfibrous PLGA-Acellular matrix scaffold for hollow organ tissue engineering. Biomaterials 34(5), 1537-1545 (2013).

26 Guex AG, Birrer DL, Fortunato G, Tevaearai HT, Giraud MN. Anisotropically oriented electrospun matrices with an imprinted periodic micropattern: a new scaffold for engineered muscle constructs. Biomed. Mater. 8(2), 21001 (2013).

27 Cheng Q, Sun Z, Meininger G, Almasri M. PDMS elastic micropost arrays for studying vascular smooth muscle cells. Sensors Actuators B Chem. 188, 1055-1063 (2013).

28 Palchesko RN, Zhang L, Sun Y, Feinberg AW. Development of polydimethylsiloxane substrates with tunable elastic modulus to study cell mechanobiology in muscle and nerve. PLoS ONE 7(12), e51499 (2012).

29 Bratt-Leal AM, Kepple KL, Carpenedo RL, Cooke MT, McDevitt TC. Magnetic manipulation and spatial patterning of multi-cellular stem cell aggregates. Integr. Biol. 3(12), 1224-1232 (2011).

30 Rutz AL, Hyland KE, Jakus AE, Burghardt WR, Shah RN. A multimaterial bioink method for 3D printing tunable, cellcompatible hydrogels. Adv. Mater. 27(9), 1607-1614 (2015).

31 Cui H, Zhu W, Holmes B, Zhang LG. 3D bioprinting: biologically inspired smart release system based on 3D bioprinted perfused scaffold for vascularized tissue regeneration. Adv. Sci. 3(8), 1600058 (2016).

32 Fabiilli ML, Wilson CG, Padilla F, Martín-Saavedra FM, Fowlkes JB, Franceschi RT. Acoustic droplet-hydrogel composites for spatial and temporal control of growth factor delivery and scaffold stiffness. Acta Biomater. 9(7), 7399-7409 (2013) 
33 Wylie RG, Ahsan S, Aizawa Y, Maxwell KL, Morshead CM, Shoichet MS. Spatially controlled simultaneous patterning of multiple growth factors in three-dimensional hydrogels. Nat. Mater. 10 (10), 799-806 (2011).

34 Liu W, Lipner J, Xie J, Manning CN, Thomopoulos S, Xia Y. Nanofiber scaffolds with gradients in mineral content for spatial control of osteogenesis. ACS Appl. Mater. Interfaces 6(4), 2842-2849 (2014).

35 Baker BM, Trappmann B, Stapleton SC, Toro E, Chen CS. Microfluidics embedded within extracellular matrix to define vascular architectures and pattern diffusive gradients. $L a b$ Chip 13(16), 3246-3252 (2013).

36 Kim BJ, Chu I, Jusuf S et al. Oxygen tension and riboflavin gradients cooperatively regulate the migration of Shewanella oneidensis MR-1 revealed by a hydrogel-based microfluidic device. Front. Microbiol. 7, 1438 (2016).

$37 \mathrm{Ma} \mathrm{H}$, Jiang Q, Han S et al. Multicellular tumor spheroids as an in vivo-like tumor model for three-dimensional imaging of chemotherapeutic and nano material cellular penetration. Mol. Imaging 11(6), 2012-7290 (2012).

38 Lan S-F, Starly B. Alginate based 3D hydrogels as an in vitro coculture model platform for the toxicity screening of new chemical entities. Toxicol. Appl. Pharmacol. 256(1), 62-72 (2011).

39 Puperi DS, Balaoing LR, O'Connell RW, West JL, Grande-Allen KJ. 3-Dimensional spatially organized PEG-based hydrogels for an aortic valve coculture model. Biomaterials 67, 354-364 (2015).

40 Masoumi N, Annabi N, Assmann A et al. Tri-layered elastomeric scaffolds for engineering heart valve leaflets. Biomaterials 35(27), 7774-7785 (2014).

41 Rossi A, Wistlich L, Heffels K, Walles H, Groll J. Isotropic versus bipolar functionalized biomimetic artificial basement membranes and their evaluation in long-term human cell coculture. Adv. Healthc. Mater. doi:10.1002/ adhm.201600224 (2016) (Epub ahead of print).

42 Shin Y, Han S, Jeon JS et al. Microfluidic assay for simultaneous culture of multiple cell types on surfaces or within hydrogels. Nat. Protoc. 7(7), 1247-1259 (2012).

- Describes a simple polydimethylsiloxane microfluidic assay for $3 \mathrm{D}$ cell culture.

43 Yeon JH, Ryu HR, Chung M, Hu QP, Jeon NL. In vitro formation and characterization of a perfusable threedimensional tubular capillary network in microfluidic devices. Lab Chip 12(16), 2815-2822 (2012).

44 Jeong S-Y, Lee J-H, Shin Y, Chung S, Kuh H-J. Coculture of tumor spheroids and fibroblasts in a collagen matrixincorporated microfluidic chip mimics reciprocal activation in solid tumor microenvironment. PLoS ONE 11(7), e0159013 (2016).

45 Metzger W, Sossong D, Bächle A et al. The liquid overlay technique is the key to formation of coculture spheroids consisting of primary osteoblasts, fibroblasts and endothelial cells. Cytotherapy 13(8), 1000-1012 (2011).

46 Jun Y, Kang AR, Lee JS et al. 3D co-culturing model of primary pancreatic islets and hepatocytes in hybrid spheroid to overcome pancreatic cell shortage. Biomaterials 34(15), 3784-3794 (2013).
47 Xu F, Celli J, Rizvi I, Moon S, Hasan T, Demirci U. A threedimensional in vitro ovarian cancer coculture model using a high throughput cell patterning platform. Biotechnol. J. 6(2), 204-212 (2011).

48 Snyder J, Son AR, Hamid Q, Wu H, Sun W. Hetero-cellular prototyping by synchronized multi-material bioprinting for rotary cell culture system. Biofabrication 8(1), 15002 (2016).

49 Nguyen LH, Kudva AK, Saxena NS, Roy K. Engineering articular cartilage with spatially-varying matrix composition and mechanical properties from a single stem cell population using a multi-layered hydrogel. Biomaterials 32(29), 6946-6952 (2011).

50 Yang C, DelRio FW, Ma H et al. Spatially patterned matrix elasticity directs stem cell fate. Proc. Natl Acad. Sci. USA 113(31), E4439-E4445 (2016).

51 Zhang Q, Lu H, Kawazoe N, Chen G. Pore size effect of collagen scaffolds on cartilage regeneration. Acta Biomater. 10(5), 2005-2013 (2014).

52 Scaffaro R, Lopresti F, Botta L, Rigogliuso S, Ghersi G. Integration of PCL and PLA in a monolithic porous scaffold for interface tissue engineering. J. Mech. Behav. Biomed. Mater. 63, 303-313 (2016).

53 Huh D, Leslie DC, Matthews BD et al. A human disease model of drug toxicity-induced pulmonary edema in a lungon-a-chip microdevice. Sci. Transl. Med. 4(159), 159ra147159ra147 (2012).

- Important model for microfluidic lung-on-a-chip.

54 Solomon DE, Abdel-Raziq A, Vanapalli SA. A stresscontrolled microfluidic shear viscometer based on smartphone imaging. Rheology Acta 55(9), 727-738 (2016).

55 Montel F, Delarue M, Elgeti J, Vignjevic D, Cappello G, Prost J. Isotropic stress reduces cell proliferation in tumor spheroids. New J. Phys. 14(5), 55008 (2012).

56 Schuurman W, Khristov V, Pot MW, van Weeren PR, Dhert WJ, Malda J. Bioprinting of hybrid tissue constructs with tailorable mechanical properties. Biofabrication 3(2), 21001 (2011).

57 Lee JW, Choi Y-J, Yong W-J et al. Development of a 3D cell printed construct considering angiogenesis for liver tissue engineering. Biofabrication 8(1), 15007 (2016).

58 Ananthanarayanan B, Kim Y, Kumar S. Elucidating the mechanobiology of malignant brain tumors using a brain matrix-mimetic hyaluronic acid hydrogel platform. Biomaterials 32(31), 7913-7923 (2011).

59 McCoy MG, Seo BR, Choi S, Fischbach C. Collagen I hydrogel microstructure and composition conjointly regulate vascular network formation. Acta Biomater. 44, 200-208 (2016).

60 Xue N, Li X, Bertulli C et al. Rapid patterning of 1-D collagenous topography as an ECM protein fibril platform for image cytometry. PLoS ONE 9(4), e93590 (2014).

61 Christopherson GT, Song H, Mao H-Q. The influence of fiber diameter of electrospun substrates on neural stem cell differentiation and proliferation. Biomaterials 30(4), 556-564 (2009).

62 Lee JS, Romero R, Han YM et al. Placenta-on-a-chip: a novel platform to study the biology of the human placenta. J. Matern. Neonatal Med. 29(7), 1046-1054 (2016). 
63 Wallin P, Zandén C, Carlberg B, Erkenstam NH, Liu J, Gold J. A method to integrate patterned electrospun fibers with microfluidic systems to generate complex microenvironments for cell culture applications. Biomicrofluidics 6(2), 24131 (2012).

64 Muranen T, Selfors LM, Worster DT et al. Inhibition of $\mathrm{PI} 3 \mathrm{~K} / \mathrm{mTOR}$ leads to adaptive resistance in matrix-attached cancer cells. Cancer Cell. 21(2), 227-239 (2012).

65 Bao J, Wu Q, Wang Y et al. Enhanced hepatic differentiation of rat bone marrow-derived mesenchymal stem cells in spheroidal aggregate culture on a decellularized liver scaffold. Int. J. Mol. Med. 38(2), 457-465 (2016).

66 Hockaday LA, Kang KH, Colangelo NW et al. Rapid 3D printing of anatomically accurate and mechanically heterogeneous aortic valve hydrogel scaffolds. Biofabrication 4(3), 35005 (2012).

67 Kumar A, Nune KC, Misra RDK. Biological functionality of extracellular matrix-ornamented three-dimensional printed hydroxyapatite scaffolds. J. Biomed. Mater. Res. Part A 104A, 1343-1351 (2016).

68 Park KM, Gerecht S. Hypoxia-inducible hydrogels. Nat. Commun. 5, 4075 (2014).

69 Wu C, Zhou Y, Fan W et al. Hypoxia-mimicking mesoporous bioactive glass scaffolds with controllable cobalt ion release for bone tissue engineering. Biomaterials 33(7), 2076-2085 (2012).

70 Wang L, Liu W, Wang Y et al. Construction of oxygen and chemical concentration gradients in a single microfluidic device for studying tumor cell-drug interactions in a dynamic hypoxia microenvironment. Lab Chip 13(4), 695-705 (2013).

71 Brennan MD, Rexius-Hall ML, Eddington DT. A 3D-printed oxygen control insert for a 24-well plate. PLoS ONE 10(9), e0137631 (2015).

72 Al-Haque S, Miklas JW, Feric N et al. Hydrogel substrate stiffness and topography interact to induce contact guidance in cardiac fibroblasts. Macromol. Biosci. 12(10), 1342-1353 (2012).

73 Sanen K, Paesen R, Luyck S et al. Label-free mapping of microstructural organisation in self-aligning cellular collagen hydrogels using image correlation spectroscopy. Acta Biomater. 30, 258-264 (2016).

74 Tung C, Ardon F, Fiore AG, Suarez SS, Wu M. Cooperative roles of biological flow and surface topography in guiding sperm migration revealed by a microfluidic model. Lab Chip 14(7), 1348-1356 (2014).

75 Zhou J, Khodakov DA, Ellis AV, Voelcker NH. Surface modification for PDMS-based microfluidic devices. Electrophoresis 33(1), 89-104 (2012).

76 Kapur SK, Wang X, Shang $\mathrm{H}$ et al. Human adipose stem cells maintain proliferative, synthetic and multipotential properties when suspension cultured as self-assembling spheroids. Biofabrication 4(2), 25004 (2012).

77 Soman P, Chung PH, Zhang AP, Chen S. Digital microfabrication of user-defined 3D microstructures in cell-laden hydrogels. Biotechnol. Bioeng. 110(11), 3038-3047 (2013).
78 Rhee S, Puetzer JL, Mason BN, Reinhart-King CA, Bonassar LJ. 3D bioprinting of spatially heterogeneous collagen constructs for cartilage tissue engineering. ACS Biomater. Sci. Eng. 2(10), 1800-1805 (2016).

79 Soroush F, Zhang T, King DJ et al. A novel microfluidic assay reveals a key role for protein kinase $\mathrm{C}$ delta in regulating human neutrophil-endothelium interaction. J. Leukoc. Biol. 100 (5), 1027-1035 (2016).

80 Wang X, Phan DTT, Sobrino A, George SC, Hughes CCW, Lee AP. Engineering anastomosis between living capillary networks and endothelial cell-lined microfluidic channels. Lab Chip 16(2), 282-290 (2016).

81 Vulto P, Podszun S, Meyer P, Hermann C, Manz A, Urban GA. Phaseguides: a paradigm shift in microfluidic priming and emptying. Lab Chip 11(9), 1596-1602 (2011).

82 Lane SW, Williams DA, Watt FM. Modulating the stem cell niche for tissue regeneration. Nat. Biotechnol. 32(8), 795-803 (2014).

83 Magin CM, Alge DL, Anseth KS. Bio-inspired 3D microenvironments: a new dimension in tissue engineering. Biomed. Mater. 11(2), 22001 (2016).

84 Zdeblick MJ, Barth PP, Angell JB. A microminiature fluidic amplifier. Sensors and Actuators 15(4), 427-433 (1988).

85 Verpoorte EMJ, Schoot Van Der BH, Jeanneret S, Manz A, Widmer HM, De Rooij NF. Three-dimensional micro flow manifolds for miniaturized chemical analysis systems. J. Micromech. Microeng. 4(4), 246-256 (1994).

86 Frame MDS, Sarelius IH. A system for culture of endothelial cells in 20-50- $\mu \mathrm{m}$ branching tubes. Microcirculation 2(4), 377-385 (1995).

87 Duffy DC, McDonald JC, Schueller OJA, Whitesides GM. Rapid prototyping of microfluidic systems in poly(dimethylsiloxane). Anal. Chem. 70 (23), 4974-4984 (1998).

- Introduces a rapid microfluidic fabrication method using poly(dimethylsiloxane) (PDMS).

88 Kinahan DJ, Kearney SM, Kilcawley NA, Early PL, Glynn MT, Ducrée J. Density-gradient mediated band extraction of leukocytes from whole blood using centrifugo-pneumatic siphon valving on centrifugal microfluidic discs. PLoS ONE 11(5), e0155545 (2016).

89 Prabhakarpandian B, Shen M-C, Nichols JB et al. SyM-BBB: a microfluidic blood brain barrier model. Lab Chip 13(6), 1093-1101 (2013).

90 Wu H-W, Hsiao Y-H, Chen C-C, Yet S-F, Hsu C-H. A PDMS-based microfluidic hanging drop chip for embryoid body formation. Molecules 21(7), 882 (2016).

91 Pit AM, Bonestroo S, Wijnperlé D, Duits MHG, Mugele F. Electrode-assisted trapping and release of droplets on hydrophilic patches in a hydrophobic microchannel. Microfluid. Nanofluidics 20 (9), 123 (2016).

92 Zhao S, Chen Y, Partlow BP et al. Bio-functionalized silk hydrogel microfluidic systems. Biomaterials 93, 60-70 (2016).

93 Liu H, Yu X, Cai B et al. Capture and release of cancer cells using electrospun etchable $\mathrm{MnO} 2$ nanofibers integrated in microchannels. Appl. Phys. Lett. 106(9), 93703 (2015). 
94 Bhatia SN, Ingber DE. Microfluidic organs-on-chips. Nat. Biotech. 32(8), 760-772 (2014).

- Discusses advantages, applications and potential of microfluidic organ-on-chips.

95 Mosig AS. Organ-on-chip models: new opportunities for biomedical research. Future Sci. OA doi:10.4155/fsoa-20160038 (2016) (Epub ahead of print).

96 Simon T, Coquerel B, Petit A et al. Direct effect of bevacizumab on glioblastoma cell lines in vitro. Neuromol. Med. 16(4), 752-771 (2014).

97 Demange E, Kassim Y, Petit C et al. Survival of cord blood haematopoietic stem cells in a hyaluronan hydrogel for $e x$ vivo biomimicry. J. Tissue Eng. Regen. Med. 7(11), 901-910 (2013).

98 Vivares A, Salle-Lefort S, Arabeyre-Fabre C et al. Morphological behaviour and metabolic capacity of cryopreserved human primary hepatocytes cultivated in a perfused multiwell device. Xenobiotica 45(1), 29-44 (2015).

99 Domansky K, Inman W, Serdy J, Dash A, Lim MHM, Griffith LG. Perfused multiwell plate for 3D liver tissue engineering. Lab Chip 10(1), 51-58 (2010).

100 Wevers NR, van Vught R, Wilschut KJ et al. High throughput compound evaluation on 3D networks of neurons and glia in a microfluidic platform. Sci. Rep. 6, 38856 (2016).

101 Wilmer MJ, Ng CP, Lanz HL, Vulto P, Suter-Dick L, Masereeuw R. Kidney-on-a-chip technology for druginduced nephrotoxicity screening. Trends Biotechnol. 34(2), 156-170 (2017).

102 Lamberti G, Soroush F, Smith A, Kiani MF, Prabhakarpandian B, Pant K. Adhesion patterns in the microvasculature are dependent on bifurcation angle. Microvasc. Res. 99, 19-25 (2015).

103 Prabhakarpandian B, Shen M-C, Nichols JB et al. Synthetic tumor networks for screening drug delivery systems. J. Control. Release 201, 49-55 (2015).

104 Hendriks DFG, Puigvert LF, Messner S, Mortiz W, Ingelman-Sundberg M. Hepatic 3D spheroid models for the detection and study of compounds with cholestatic liability. Sci. Rep. 6, 35434 (2016).

105 Kermanizadeh A, Lohr M, Roursgaard M et al. Hepatic toxicology following single and multiple exposure of engineered nanomaterials utilising a novel primary human 3D liver microtissue model. Part. Fibre Toxicol. 11, 56 (2014).

106 Norona LM, Nguyen DG, Gerber DA, Presnell SC, LeCluyse EL. Modeling compound-induced fibrogenesis in vitro using three-dimensional bioprinted human liver tissues. Toxicol. Sci. 154(2), 354-367 (2016).

107 Nguyen DG, Funk J, Robbins JB et al. Bioprinted 3D primary liver tissues allow assessment of organ-level response to clinical drug induced toxicity in vitro. PLoS ONE 11(7), e0158674 (2016).

108 Kim HJ, Huh D, Hamilton G, Ingber DE. Human guton-a-chip inhabited by microbial flora that experiences intestinal peristalsis-like motions and flow. Lab Chip 12(12), 2165-2174 (2012).
109 Jang K-J, Mehr AP, Hamilton GA et al. Human kidney proximal tubule-on-a-chip for drug transport and nephrotoxicity assessment. Integr. Biol. (Camb.) 5(9), 1119-1129 (2013).

110 Maschmeyer I, Lorenz AK, Schimek K et al. A four-organchip for interconnected long-term coculture of human intestine, liver, skin and kidney equivalents. Lab Chip 15(12), 2688-2699 (2015).

111 Berdichevsky Y, Staley KJ, Yarmush ML. Building and manipulating neural pathways with microfluidics. Lab Chip 10(8), 999-1004 (2010).

112 Han S, Yang K, Shin Y et al. Three-dimensional extracellular matrix-mediated neural stem cell differentiation in a microfluidic device. Lab Chip 12(13), 2305-2308 (2012).

113 Luni C, Serena E, Elvassore N. Human-on-chip for therapy development and fundamental science. Curr. Opin. Biotechnol. 25, 45-50 (2014).

114 Ballabh P, Braun A, Nedergaard M. The blood-brain barrier: an overview: structure, regulation, and clinical implications. Neurobiol. Dis. 16(1), 1-13 (2004).

115 Hislop AA. Airway and blood vessel interaction during lung development. J. Anat. 201(4), 325-334 (2002).

116 Mueller CB. The structure of the renal glomerulus. Am. Heart J. 55(2), 304-322 (1958).

117 Ohayon J, Finet G, Gharib AM et al. Necrotic core thickness and positive arterial remodeling index: emergent biomechanical factors for evaluating the risk of plaque rupture. Am. J. Physiol. Circ. Physiol. 295(2), H717-H727 (2008).

118 Magrini E, Villa A, Angiolini F et al. Endothelial deficiency of $\mathrm{L} 1$ reduces tumor angiogenesis and promotes vessel normalization. J. Clin. Invest. 124(10), 4335-4350 (2014).

119 Lee J-H, Bhang DH, Beede A et al. Lung stem cell differentiation in mice directed by endothelial cells via a BMP4-NFATc1-thrombospondin-1 axis. Cell 156(3), 440-455 (2014).

120 Kubota T, Kubota N, Kadowaki T. The role of endothelial insulin signaling in the regulation of glucose metabolism. Rev. Endocr. Metab. Disord. 14(2), 207-216 (2013).

121 Belcher JD, Chen C, Nguyen J et al. The fucosylation inhibitor, 2-fluorofucose, inhibits vaso-occlusion, leukocyteendothelium interactions and NF- $\mathrm{\kappa B}$ activation in transgenic sickle mice. PLoS ONE 10(2), e0117772 (2015).

122 Gerdes N, Seijkens T, Lievens D et al. Platelet CD 40 exacerbates atherosclerosis by transcellular activation of endothelial cells and leukocytes. Arterioscler. Thromb. Vasc. Biol. 36(3), 482-490 (2016).

123 Muller WA. How endothelial cells regulate transmigration of leukocytes in the inflammatory response. Am. J. Pathol. 184(4), 886-896 (2014).

124 Huveneers S, Daemen MJAP, Hordijk PL. Between rho (k) and a hard place: the relation between vessel wall stiffness, endothelial contractility, and cardiovascular disease. Circ. Res. 116(5), 895-908 (2015).

125 Harney AS, Arwert EN, Entenberg D, Wang Y, Jones JG, Condeelis JS. Perivascular macrophages induce localized, transient blood vessel permeability and tumor cell intravasation. Cancer Res. 74 (Suppl. 19), 4940 (2014). 
126 Correa D, Somoza RA, Lin P, Schiemann WP, Caplan AI. Mesenchymal stem cells regulate melanoma cancer cells extravasation to bone and liver at their perivascular niche. Int. J. Cancer 138(2), 417-427 (2016).

127 Farahat WA, Wood LB, Zervantonakis IK et al. Ensemble analysis of angiogenic growth in three-dimensional microfluidic cell cultures. PLoS ONE 7(5), e37333 (2012).

128 Bogorad MI, DeStefano J, Karlsson J, Wong AD, Gerecht $S$, Searson PC. Review: in vitro microvessel models. Lab Chip 15(22), 4242-4255 (2015).

129 Tsai M, Kita A, Leach J et al. In vitro modeling of the microvascular occlusion and thrombosis that occur in hematologic diseases using microfluidic technology. J. Clin. Invest. 122(1), 408-418 (2012).

130 Chung S, Sudo R, Vickerman V, Zervantonakis IK, Kamm RD. Microfluidic platforms for studies of angiogenesis, cell migration, and cell-cell interactions. Ann. Biomed. Eng. 38(3), 1164-1177 (2010).

131 Businaro L, De Ninno A, Schiavoni G et al. Cross talk between cancer and immune cells: exploring complex dynamics in a microfluidic environment. Lab Chip 13(2), 229-239 (2013).

132 Buchanan CF, Verbridge SS, Vlachos PP, Rylander MN Flow shear stress regulates endothelial barrier function and expression of angiogenic factors in a 3D microfluidic tumor vascular model. Cell Adh. Migr. 8(5), 517-524 (2014).

133 Zervantonakis IK, Hughes-Alford SK, Charest JL, Condeelis JS, Gertler FB, Kamm RD. Three-dimensional microfluidic model for tumor cell intravasation and endothelial barrier function. Proc. Natl Acad. Sci. USA 109(34), 13515-13520 (2012).

134 Zheng $\mathrm{Y}$, Chen J, Craven $\mathrm{M}$ et al. In vitro microvessels for the study of angiogenesis and thrombosis. Proc. Natl Acad. Sci. USA 109(24), 9342-9347 (2012).

135 Wong KHK, Chan JM, Kamm RD, Tien J. Microfluidic models of vascular functions. Annu. Rev. Biomed. Eng. 14(1), 205-230 (2012).

136 Traktuev DO, Merfeld-Clauss S, Li J et al. A population of multipotent CD34-positive adipose stromal cells share pericytes and mesenchymal surface markers, reside in a periendothelial location, and stabilize endothelial networks. Circ. Res. 102(1), 77-85 (2008).

137 Hughes CCW. Endothelial-stromal interactions in angiogenesis. Curr. Opin. Hematol. 15(3), 204-209 (2008).

138 Miller JS, Stevens KR, Yang MT et al. Rapid casting of patterned vascular networks for perfusable engineered threedimensional tissues. Nat. Mater. 11(9), 768-774 (2012).

139 Borenstein JT, Tupper MM, Mack PJ et al. Functional endothelialized microvascular networks with circular cross-sections in a tissue culture substrate. Biomed. Microdevices 12(1), 71-79 (2010).

140 Bischel LL, Young EWK, Mader BR, Beebe DJ. Tubeless microfluidic angiogenesis assay with three-dimensional endothelial-lined microvessels. Biomaterials 34(5), 1471-1477 (2013).

141 Wong AD, Searson PC. Live-cell imaging of invasion and intravasation in an artificial microvessel platform. Cancer Res. 74(17), 4937-4945 (2014).
142 Sarig-Nadir O, Livnat N, Zajdman R, Shoham S, Seliktar $D$. Laser photoablation of guidance microchannels into hydrogels directs cell growth in three dimensions. Biophys. J. 96(11), 4743-4752 (2009).

143 Hasan A, Paul A, Memic A, Khademhosseini A. A multilayered microfluidic blood vessel-like structure. Biomed. Microdevices 17(5), 88 (2015).

144 Mannino R, Myers DR, Ahn B et al. Vascular geometry and flow profile mediate pathological cell-cell interactions in sickle cell disease as measured with "do-it-yourself" “endothelial-ized” microfluidics. Blood 124(21), 454 (2014).

145 Hasan A, Paul A, Vrana NE et al. Microfluidic techniques for development of 3D vascularized tissue. Biomaterials 35(26), 7308-7325 (2014)

146 Nguyen D-HT, Stapleton SC, Yang MT et al. Biomimetic model to reconstitute angiogenic sprouting morphogenesis in vitro. Proc. Natl Acad. Sci. USA 110(17), 6712-6717 (2013).

147 Sackmann EK, Fulton AL, Beebe DJ. The present and future role of microfluidics in biomedical research. Nature 507(7491), 181-189 (2014).

148 Villasante A, Vunjak-Novakovic G. Tissue-engineered models of human tumors for cancer research. Expert Opin. Drug Discov. 10(3), 257-268 (2015).

149 Peng W, Unutmaz D, Ozbolat IT. Bioprinting towards physiologically relevant tissue models for pharmaceutics. Trends Biotechnol. 34(9), 722-732 (2016).

150 Wan ACA. Recapitulating cell-cell interactions for organoid construction - are biomaterials dispensable? Trends Biotechnol. 34(9), 711-721 (2016).

151 Kellogg RA, Gómez-Sjöberg R, Leyrat AA, Tay S. High throughput microfluidic single-cell analysis pipeline for studies of signaling dynamics. Nat. Protoc. 9(7), 1713-1726 (2014).

152 Hughes AJ, Spelke DP, Xu Z, Kang C-C, Schaffer DV, Herr AE. Single-cell western blotting. Nat. Meth. 11(7), 749-755 (2014).

153 Shih SCC, Barbulovic-Nad I, Yang X, Fobel R, Wheeler AR Digital microfluidics with impedance sensing for integrated cell culture andanalysis. Biosens. Bioelectron. 42, 314-320 (2013).

154 Huh D, Kim HJ, Fraser JP et al. Microfabrication of human organs-on-chips. Nat. Protoc. 8(11), 2135-2157 (2013).

- Protocol for the fabrication and operation of microfluidic organ-on-a-chip systems.

155 Young EWK, Berthier E, Guckenberger DJ et al. Rapid prototyping of arrayed microfluidic systems in polystyrene for cell-based assays. Anal. Chem. 83(4), 1408-1417 (2011).

156 Knowlton S, Yenilmez B, Tasoglu S. Towards single-step biofabrication of organs on a chip via $3 \mathrm{D}$ printing. Trends Biotechnol. 34(9), 685-688 (2017).

157 Fitzgerald KA, Guo J, Raftery RM et al. Nanoparticlemediated siRNA delivery assessed in a 3D coculture model simulating prostate cancer bone metastasis. Int. J. Pharm. 511(2), 1058-1069 (2016).

$158 \mathrm{Xu} \mathrm{Z}, \mathrm{Li}$ E, Guo Z et al. Design and construction of a multi-organ microfluidic chip mimicking the in vivo 
microenvironment of lung cancer metastasis. ACS Appl. Mater. Interfaces 8(39), 25840-25847 (2016).

159 Kuo C-T, Chiang C-L, Chang C-H et al. Modeling of cancer metastasis and drug resistance via biomimetic nano-cilia and microfluidics. Biomaterials 35(5), 1562-1571 (2014).

160 Mi S, Du Z, Xu Y et al. Microfluidic coculture system for cancer migratory analysis and anti-metastatic drugs screening. Sci. Rep. 6, 35544 (2016).
161 Sung JH, Shuler ML. A micro cell culture analog (microCCA) with 3-D hydrogel culture of multiple cell lines to assess metabolism-dependent cytotoxicity of anti-cancer drugs. Lab Chip 9(10), 1385-1394 (2009).

162 Tomlinson RE, Li Z, Zhang Q et al. NGF-TrkA signaling by sensory nerves coordinates the vascularization and ossification of developing endochondral bone. Cell Rep. 16(10), 2723-2735 (2016). 